\title{
Factors Controlling the Electrodeposition of Metal Nanoparticles on Pristine Single Walled Carbon Nanotubes
}

Thomas M. Day, Patrick R. Unwin, Julie V. Macpherson

Supporting Information: Verification of the microcapillary electrochemical cell arrangement for the investigation of redox processes at conducting surfaces

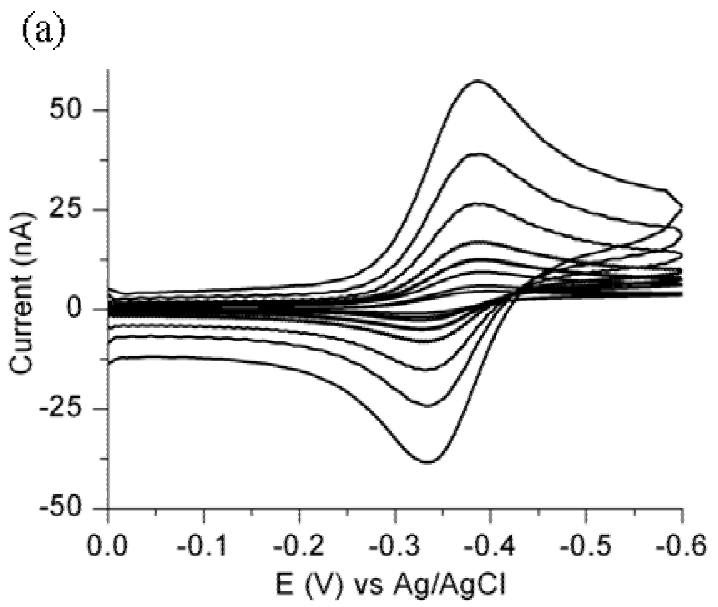

(b)

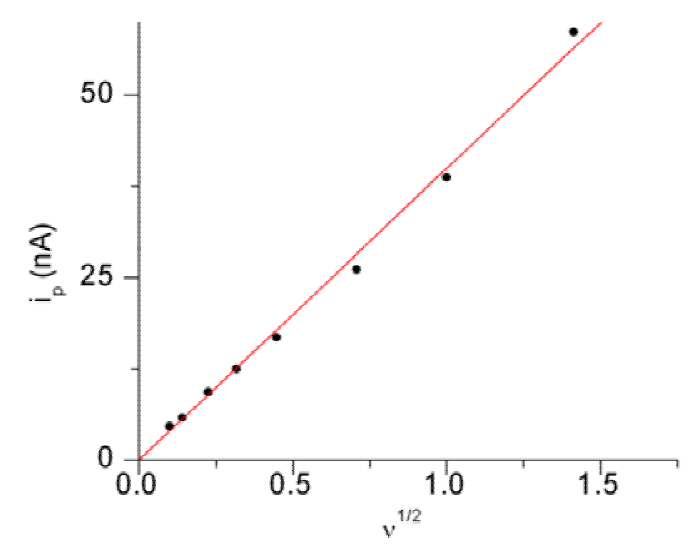

Figure 1. Plots of (a) cyclic voltammetric (CV) sweeps and (b) peak current $\left(I_{p}\right)$ vs. scan rate ${ }^{1 / 2}$ $\left(v^{I / 2}\right)$ for the reduction of $1 \mathrm{mM} \mathrm{Ru}\left(\mathrm{NH}_{3}\right)_{6}{ }^{3+}$ in $1 \mathrm{M} \mathrm{KNO}_{3}$ on an evaporated Au band, using a microcapillary of inner diameter $75 \mu \mathrm{m}$. There are eight CVs recorded at scan rates from 0.01 to $2 \mathrm{~V} \mathrm{~s}^{-1}$. The CVs have characteristics indicative of reversible electron transfer, although at the slowest scan rates $\left(0.01 \mathrm{~V} \mathrm{~s}^{-1}\right.$ and $\left.0.02 \mathrm{~V} \mathrm{~s}^{-1}\right)$ slightly larger peak separations result $(0.080$ and $0.072 \mathrm{~V}$, respectively), most likely because the CVs have partial character from a quasi-steadystate.

Assuming planar diffusion to the surface, the peak current should have a linear relationship with $v^{1 / 2}$ according to equation (1): ${ }^{1}$ 


$$
I_{p}=2.69 \times 10^{5} n^{2 / 3} A D^{1 / 2} c^{*} v^{1 / 2}
$$

where $A$ is the electrode area $\left(\mathrm{cm}^{2}\right), D$ is the diffusion coefficient $\left(8.8 \times 10^{-6} \mathrm{~cm}^{2} \mathrm{~s}^{-1}\right.$ for $\left.\mathrm{Ru}\left(\mathrm{NH}_{3}\right)_{6}{ }^{3+}\right)$ and $c^{*}$ is the bulk electrolyte concentration. The linear fit, and the value for concentration derived from the peak currents and equation 1 of $1.138 \mathrm{mM} \mathrm{Ru}\left(\mathrm{NH}_{3}\right)_{6}$, suggests that over the timescale of the experiments there is little evaporation from the capillary.

1. Bard, A. J.; Faulkner, L. R. Electrochemical Methods: Fundamentals and Applications, John Wiley, NY, 2001, p231. 